STROBE Statement — checklist of items that should be included in reports of observational studies

\begin{tabular}{|c|c|c|c|c|}
\hline & $\begin{array}{l}\text { Item } \\
\text { No. }\end{array}$ & Recommendation & $\begin{array}{l}\text { Page } \\
\text { No. }\end{array}$ & $\begin{array}{l}\text { Relevant text from } \\
\text { manuscript }\end{array}$ \\
\hline \multirow[t]{2}{*}{ Title and abstract } & \multirow[t]{2}{*}{1} & (a) Indicate the study's design with a commonly used term in the title or the abstract & 1 & \\
\hline & & $\begin{array}{l}\text { (b) Provide in the abstract an informative and balanced summary of what was done and what was } \\
\text { found }\end{array}$ & 1 & \\
\hline \multicolumn{5}{|l|}{ Introduction } \\
\hline Background/rationale & 2 & Explain the scientific background and rationale for the investigation being reported & 2 & \\
\hline Objectives & 3 & State specific objectives, including any prespecified hypotheses & 3 & \\
\hline \multicolumn{5}{|l|}{ Methods } \\
\hline Study design & 4 & Present key elements of study design early in the paper & 3 & \\
\hline Setting & 5 & $\begin{array}{l}\text { Describe the setting, locations, and relevant dates, including periods of recruitment, exposure, } \\
\text { follow-up, and data collection }\end{array}$ & 3 & \\
\hline \multirow[t]{2}{*}{ Participants } & 6 & $\begin{array}{l}\text { (a) Cohort study - Give the eligibility criteria, and the sources and methods of selection of } \\
\text { participants. Describe methods of follow-up } \\
\text { Case-control study - Give the eligibility criteria, and the sources and methods of case } \\
\text { ascertainment and control selection. Give the rationale for the choice of cases and controls } \\
\text { Cross-sectional study - Give the eligibility criteria, and the sources and methods of selection of } \\
\text { participants }\end{array}$ & 3 & \\
\hline & & $\begin{array}{l}\text { (b) Cohort study-For matched studies, give matching criteria and number of exposed and } \\
\text { unexposed } \\
\text { Case-control study-For matched studies, give matching criteria and the number of controls per } \\
\text { case }\end{array}$ & & \\
\hline Variables & 7 & $\begin{array}{l}\text { Clearly define all outcomes, exposures, predictors, potential confounders, and effect modifiers. } \\
\text { Give diagnostic criteria, if applicable }\end{array}$ & 3 & \\
\hline $\begin{array}{l}\text { Data sources/ } \\
\text { measurement }\end{array}$ & $8 *$ & $\begin{array}{l}\text { For each variable of interest, give sources of data and details of methods of assessment } \\
\text { (measurement). Describe comparability of assessment methods if there is more than one group }\end{array}$ & 3,4 & \\
\hline Bias & 9 & Describe any efforts to address potential sources of bias & $\mathrm{n} / \mathrm{a}$ & \\
\hline Study size & 10 & Explain how the study size was arrived at & 4 & \\
\hline
\end{tabular}

Continued on next page 


\begin{tabular}{|c|c|c|c|}
\hline $\begin{array}{l}\text { Quantitative } \\
\text { variables }\end{array}$ & 11 & $\begin{array}{l}\text { Explain how quantitative variables were handled in the analyses. If applicable, describe which } \\
\text { groupings were chosen and why }\end{array}$ & 3,4 \\
\hline \multirow{7}{*}{$\begin{array}{l}\text { Statistical } \\
\text { methods }\end{array}$} & \multirow[t]{7}{*}{12} & (a) Describe all statistical methods, including those used to control for confounding & 3 \\
\hline & & (b) Describe any methods used to examine subgroups and interactions & 3 \\
\hline & & (c) Explain how missing data were addressed & $\mathrm{n} / \mathrm{a}$ \\
\hline & & (d) Cohort study - If applicable, explain how loss to follow-up was addressed & \\
\hline & & Case-control study-If applicable, explain how matching of cases and controls was addressed & \\
\hline & & $\begin{array}{l}\text { Cross-sectional study - If applicable, describe analytical methods taking account of sampling } \\
\text { strategy }\end{array}$ & 3 \\
\hline & & $(\underline{e})$ Describe any sensitivity analyses & \\
\hline \multicolumn{4}{|l|}{ Results } \\
\hline \multirow[t]{3}{*}{ Participants } & \multirow[t]{3}{*}{$13 *$} & $\begin{array}{l}\text { (a) Report numbers of individuals at each stage of study - eg numbers potentially eligible, examined } \\
\text { for eligibility, confirmed eligible, included in the study, completing follow-up, and analysed }\end{array}$ & 4 \\
\hline & & (b) Give reasons for non-participation at each stage & 4 \\
\hline & & (c) Consider use of a flow diagram & Figure $\mathrm{N}^{\circ} 2$ \\
\hline \multirow[t]{3}{*}{ Descriptive data } & \multirow[t]{3}{*}{$14 *$} & $\begin{array}{l}\text { (a) Give characteristics of study participants (eg demographic, clinical, social) and information on } \\
\text { exposures and potential confounders }\end{array}$ & 4 \\
\hline & & (b) Indicate number of participants with missing data for each variable of interest & 4 \\
\hline & & (c) Cohort study-Summarise follow-up time (eg, average and total amount) & \\
\hline \multirow[t]{3}{*}{ Outcome data } & \multirow[t]{3}{*}{$15^{*}$} & Cohort study-Report numbers of outcome events or summary measures over time & \\
\hline & & Case-control study-Report numbers in each exposure category, or summary measures of exposure & \\
\hline & & Cross-sectional study-Report numbers of outcome events or summary measures & 4,5 \\
\hline \multirow[t]{4}{*}{ Main results } & \multirow[t]{4}{*}{16} & (a) Give unadjusted estimates and, if applicable, confounder-adjusted estimates and their precision & \\
\hline & & $\begin{array}{l}\text { (eg, } 95 \% \text { confidence interval). Make clear which confounders were adjusted for and why they were } \\
\text { included }\end{array}$ & 4,5 \\
\hline & & (b) Report category boundaries when continuous variables were categorized & $\mathrm{n} / \mathrm{a}$ \\
\hline & & $\begin{array}{l}\text { (c) If relevant, consider translating estimates of relative risk into absolute risk for a meaningful time } \\
\text { period }\end{array}$ & $\mathrm{n} / \mathrm{a}$ \\
\hline
\end{tabular}

Continued on next page 
Discussion

Key results

18 Summarise key results with reference to study objectives

5

Limitations

19 Discuss limitations of the study, taking into account sources of potential bias or imprecision. Discuss

5,6 both direction and magnitude of any potential bias

Interpretation 20 Give a cautious overall interpretation of results considering objectives, limitations, multiplicity of 5,6 analyses, results from similar studies, and other relevant evidence

Generalisability 21 Discuss the generalisability (external validity) of the study results $\mathrm{N} / \mathrm{a}$

\section{Other information}

Funding

Give the source of funding and the role of the funders for the present study and, if applicable, for the original study on which the present article is based

*Give information separately for cases and controls in case-control studies and, if applicable, for exposed and unexposed groups in cohort and cross-sectional studies.

Note: An Explanation and Elaboration article discusses each checklist item and gives methodological background and published examples of transparent reporting. The STROBE checklist is best used in conjunction with this article (freely available on the Web sites of PLoS Medicine at http://www.plosmedicine.org/, Annals of Internal Medicine at http://www.annals.org/, and Epidemiology at http://www.epidem.com/). Information on the STROBE Initiative is available at www.strobe-statement.org. 